\title{
Radix Paramolaris in a Second Mandibular Molar: A Case Report of an Unusual Finding
}

\section{Marta Alonso, Óliver Valencia de Pablo, Roberto Estevez*, Jorge Vera and Rafael Cisneros}

Master's in Advanced Endodontics, Universidad Europea de Madrid, Spain

*Corresponding author: Roberto Estevez, Master's in Advanced Endodontics, Universidad Europea de Madrid, Spain, E-mail: roberto.estevez@universidadeuropea.es

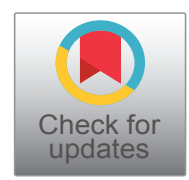

\begin{abstract}
Introduction: Chemomechanical preparation of the root canal system is extremely important during root canal therapy and, in order to achieve this goal, location of all entrances into the root canal system must be accomplished. The mandibular second molar usually has two roots and three root canals; However, there can be variations both in the number of roots as well as in the number of canals.

Methods: The clinical case presented here is a mandibular second molar with three roots, which is not a common finding.

Results: In this anatomical situation, the third root can be located either distal to or at the same level as the furcation, and it can be located buccally (radix paramolaris) or lingually (radix entomolaris). Examination of the external anatomy and number of cusps is necessary to determine the presence of the radix.

Conclusions: A follow-up examination was performed 12 months after completion of the case; The patient was asymptomatic and without radiographic signs of periradicular periodontitis. A literature review of this anatomical anomaly is also presented.
\end{abstract}

\section{Keywords}

Radix paramolaris, Mandibular second molar, Root canal treatment

\section{Introduction}

Thorough knowledge of both the external and internal anatomy of the tooth to be endodontically treated allows the clinician to clean, shape and fill the root canal system in three dimensions, which is the main purpose of nonsurgical root canal therapy [1]; However, missed root canals, which are usually anatomical variants or ex- tra canals, may compromise the prognosis of a tooth by harboring infected organic tissue [2].

Mandibular molars usually have two roots, one mesial and one distal, that typically have either one or two canals each. The most frequent anatomical variation in the mandibular first molar is the presence of a third root located in a distolingual position and its prevalence varies depending on the patient's race [2]. In contrast, the most frequent anatomical variation of the mandibular second molar is fusion of its roots [3] and a C-configuration of the root canal system [4-6]. The presence of accessory roots on this tooth has rarely been reported $[5,7,8]$.

Carabelli (1844) was the first to describe the presence of a third root (located lingually) on a mandibular molar [9]. In 1915 Bolk named it radix entomolaris (RE) [10]. This root is present in $0.7 \%$ to $4.2 \%$ of the European population [11-15]. When it is located buccally instead of lingually, it is called radix paramolaris (RP), as named by Bolk in 1914 [16]. The prevalence of RP is much lower than that of RE.

The present case is of a mandibular second molar with a third root in a buccal position (RP). Its presence is very rare; Therefore, it is considered exceptional root morphology [17].

\section{Case Report}

A 54-year-old Caucasian female arrived for consultation at the endodontic postgraduate department complaining of pain in her mandibular left quadrant. The patient's medical history was noncontributory. After 
having a thorough examination, the patient reported no pain to percussion but high sensitivity to cold in her mandibular left second molar; The molar was diagnosed as having symptomatic irreversible pulpitis.

After rubber dam isolation of the tooth, a leaking composite restoration, and caries were removed. Access into the pulp chamber was done with a No. 4 round bur; Final access was refined with an Endo-Z bur (Dentsply-Maillefer, Ballaigues, Switzerland). Location and flaring of the coronal third of the root canals was done and working length determined. Three canals were found in the mesial root, but the middle mesial and mesiobuccal canals joined once they were instrumented. A third root located distobuccally was also found and confirmed radiographically.

Instrumentation was carried out with the Mtwo sys- tem (VDW Endodontic Synergy, Munich, Germany) up to a size 25/06 in all canals. Irrigation was done between every instrument change with $2.5 \% \mathrm{NaOCl}$, maintaining patency with a No. 10 K-file. Then $17 \%$ EDTA was activated intracanal using the red 25/04 tip of the Endoactivator (Tulsa Dental, Tulsa, OK, USA) for $1 \mathrm{~min}$ to remove the smear layer, and a final irrigation was done with $2.5 \% \mathrm{NaOCl}$. After we dried the canals, filling was done by the vertical condensation technique, using System B (SybronEndo Dental Specialties, Orange, CA, USA) at $200{ }^{\circ} \mathrm{C}$ and the $1-2$ Buchanan Hand Plugger (Sybron) to condense the Autofit 0.06 gutta-percha points (Sybron) in the apical third. The two coronal thirds were filled by lateral condensation using fine gutta-percha points (Dentsply-Maillefer); And a digital spreader, Top Seal (Dentsply) was used as the sealer. Cavit G (3M ESPE, St. Paul, MN, USA) was used as a temporary filling to seal
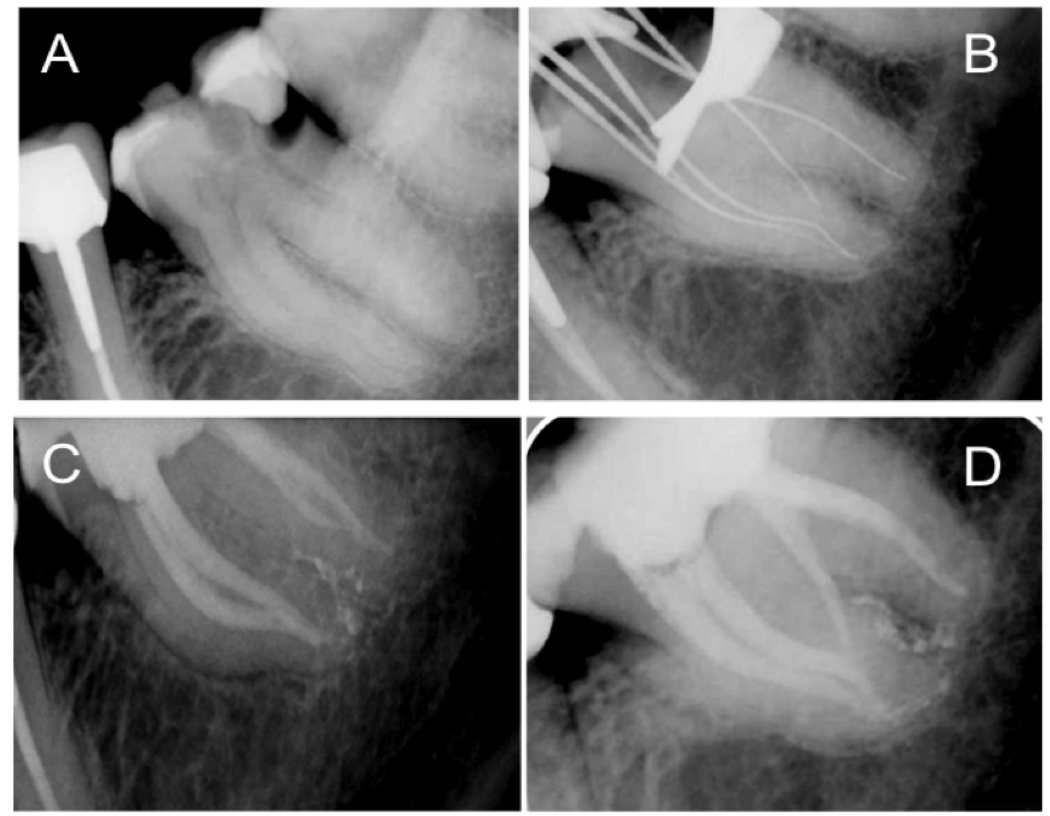

Figure 1: A) Periapical x-ray film; B) Distal working-length radiograph; C,D) Mesial and distal postoperative x-ray films.

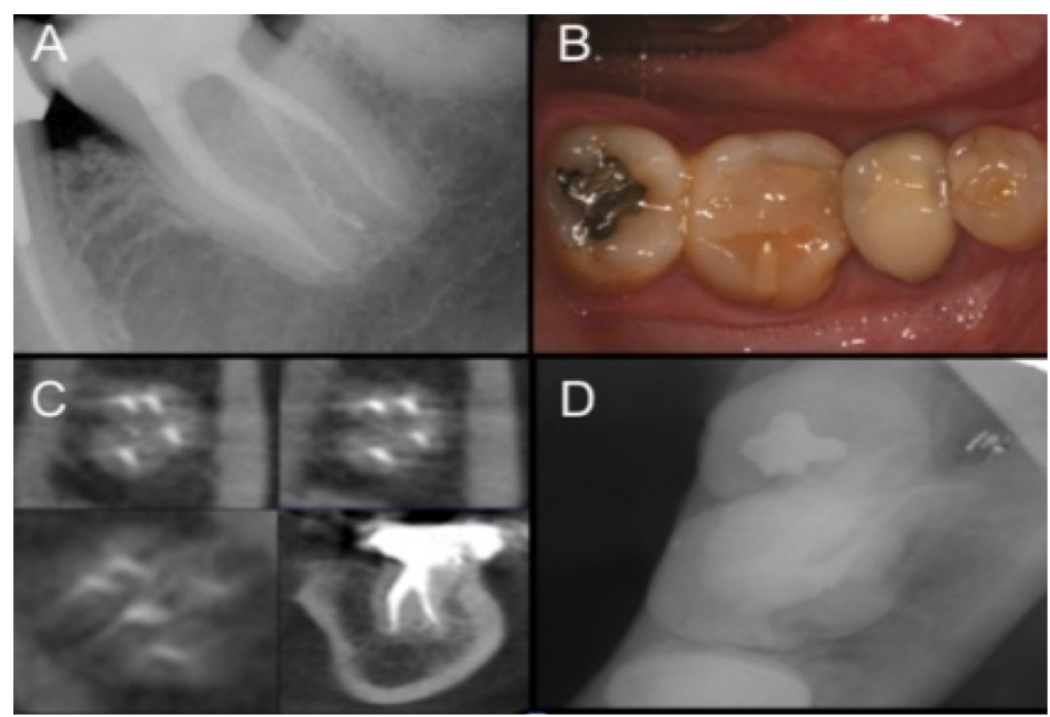

Figure 2: A) 12-month follow-up radiograph; B) Photographic occlusal view of composite reconstruction after 12 months; C) Axial and coronal sections showing buccal direction of radix paramolaris (RP); D) Occlusal radiograph showing buccal direction of RP. 
the access cavity. Final x-ray films were taken from mesial and distal angles (Figure 1).

The tooth was restored with a composite inlay almost immediately after the root canal treatment had been completed. At that time, the patient was asymptomatic, and no periradicular radiolucencies were apparent. A follow-up examination was done 12 months after treatment (Figure 2). Further examination was done by means of cone beam computed tomography (CBCT), which was indicated as part of her full-mouth restorative treatment. This showed the presence of the buccal root, or RP.

\section{Discussion}

One of the main reasons for failure of endodontically treated teeth is the presence of untreated root canals [18-25]. The mandibular second molar usually has two roots, but it might present certain internal or external anatomical variations. In their external anatomy, the roots may merge or be C-shaped. Weine [26], Gulabivala [4], Ahmed [27], Al-Qudah [6], and Lohand, et al. [28], studied the number of roots present on mandibular second molars and did not find any third roots. On the contrary, Manning examined 149 mandibular second molars and found a third root in $2 \%$ of the cases but did not specify their locations [29]. Gulavibala [5] and Rocha, et al. [7] obtained similar results, with $1.2 \%$ and $1.5 \%$ of the cases, respectively, having three roots.

In terms of internal anatomy, there are usually two canals in the mesial root and one in the distal root; Nevertheless, the most frequent morphological variant is the C-shaped canal [30].

Another anatomical peculiarity becoming a frequent finding in the mandibular first molar is the presence of a third canal in the mesial root (called the middle-mesial canal), and locating it requires a modification in the access cavity design. As with third roots, the prevalence of a middle-mesial canal in the mandibular second molar has rarely been described. In 1981, Pommeranz was the first to describe the presence of a middle canal in the mesial root of a mandibular second molar. Of the 39 second molars he evaluated, five extra canals were instrumented, and three of them merged into one of the main canals after being flared; this resulted in two canals in the mesial root, a circular one and a fin-shaped one. In the other two cases, the middle-mesial canal had a separate orifice [31]. Martínez-Berná and Badanelli [32] retrospectively evaluated 944 cases of treated mandibular second molars, finding a third canal in $0.42 \%$.

In the present case, we initially observed three canals on the working-length x-ray image; However, once they were instrumented, the middle-mesial canal merged with the mesiobuccal one, resulting in a fin-shaped canal.

An RE or RP implies the presence of a canal that is not only difficult to locate, but also difficult to clean and shape. De Moor, et al. [33] described this complexity in the anatomy of RE in which the root curvature is usually different from the other roots in the same tooth.

The presence of RE varies among races, ranging from $3.4 \%$ in the European population to $40 \%$ among Mongoloids. The presence of RP, as in the case here, is much lower. References show that a third buccal root in mandibular molars occurs in only $0.5 \%$ of the cases [17,34], which makes this case peculiar. To our knowledge, only one case report of an RP in the mandibular second molar has been published [17].

Carlsen and Alexander [34] carried out the most exhaustive case study of radix roots in mandibular molars with a sample of 203 paramolaris roots, out of which 136 were in the mandibular second molar. Based on the classification suggested by them, our case report corresponds to a type $B$, wherein the buccal part of the root complex consisted of three cone-shaped macrostructures: One central, one mesial, and one distal. Because the roots were so close to each other, we could not confirm whether it was a completely independent root or one that had merged with the distal one; however, the distally angled x-ray image clearly showed that it had an independent apical foramen.

The presence of a third root on the mandibular second molar also has clinical implications. Detecting its presence can prevent complications such as leaving a canal untreated. In most instances, taking radiographs from different angles or carefully observing the clinical crown can help detect the presence of the extra root [35]. In this case, none of the x-ray films taken before, during, or after treatment showed the exact contour of the radix root because of its position. Superimposed roots on the radiograph can result in an incorrect diagnosis; That is why it is also important to thoroughly inspect the morphology of the crown. In this case, however, the presence of a previous filling and recurrent decay prevented a correct diagnosis.

One-year post-treatment and during the follow-up appointment, conventional periapical and occlusal x-ray films were taken, as well as CBCT, in which we can appreciate, although with some difficulty, the presence of the RP. CBCT is a complementary diagnostic technique that is becoming more popular in dentistry, especially in endodontics.

The presence of an extra root is sometimes associated with changes in occlusal anatomy. Seperber and Moreau showed that $20 \%$ of molars having an additional root also possess an extra cusp that is situated between the two lingual ones, suggesting the presence of a distolingual root. In their observational study, $100 \%$ of the molars with an extra cusp proved to have an additional root [35]. Calberson, et al. [17] confirmed this finding in their article wherein they examined mandibular molars having extra roots, finding an extra cusp on the buccal 
side of a mandibular third molar and a paramolaris root. Careful analysis of the contralateral tooth can also help detect the presence of an RE or an RP, since there is a strong likelihood of bilateral occurrence of this anatomical variation [36]. In this case report, the mandibular right second molar was absent, making diagnosis more difficult.

\section{References}

1. Schilder $H$ (1974) Cleaning and shaping the root canal. Dent Clin North Am 18: 269-296.

2. Segura-Egea JJ, Jimenez-Pinzon A, Rios-Santos JV (2002) Endodontic therapy in a 3-rooted mandibular first molar: Importance of a thorough radiographic examination. J Can Dent Assoc 68: 541-544.

3. Rwenyonyi CM, Kutesa A, Muwazi LM, Buwembo W (2009) Root and canal morphology of mandibular first and second permanent molar teeth in a Ugandan population. Odontology 97: 92-96.

4. Gulabivala K, Aung TH, Alavi A, Ng YL (2001) Root and canal morphology of burmese mandibular molars. Int Endod J 34: 359-370.

5. Gulabivala K, Opasanon A, Ng YL, Alavi A (2002) Root and canal morphology of thai mandibular molars. Int Endod J 35: 56-62.

6. Al-Qudah AA, Awawdeh LA (2009) Root and canal morphology of mandibular first and second molar teeth in a jordanian population. Int Endod J 42: 775-784.

7. Rocha LF, Sousa Neto MD, Fidel SR, da Costa WF, Pecora JD (1996) External and internal anatomy of mandibular molars. Braz Dent J 7: 33-40.

8. Peiris R, Takahashi M, Sasaki K, Kanazawa E (2007) Root and canal morphology of permanent mandibular molars in a Sri Lankan population. Odontology 95: 16-23.

9. Carabelli G (1844) Systematisches Handbuchder Zahnheikunde. ( $2^{\text {nd }}$ edn), Vienna: Braumullerand Seidel 1844: 114.

10. Bolk L (1915) Bemerküngenüber Wurzel variation enammen schlichenunteren Molaren. Zeiting fur Morphologie und Anthropologie 17: 605-610.

11. Schäfer E, Breuer D, Janzen S (2009) The prevalence of three-rooted mandibular permanent first molars in a German population. J Endod 35: 202-205.

12. De Souza-Freitas JA, Lopes ES, Casati-Alvares L (1971) Anatomic variations of lower first permanent molar roots in two ethnic groups. Oral Surg Oral Med Oral Pathol 31: 274278.

13. Skidmore AE, Bjorndahl AM (1971) Root canal morphology of the human mandibular first molar. Oral Surg Oral Med Oral Pathol 32: 778-784.

14. Curzon ME (1973) Three-rooted mandibular permanent molars in English Caucasians. J Dent Res 52: 181.

15. Ferraz JA, Pécora JD (1993) Three rooted mandibular molars in patients of Mongolian, Caucasian and Negro origin. Braz Dent J 3: 113-117.

16. Bolk L (1914) Welcher Gebi reihe gehören die Molaren. Z Morphol Anthropol 17: 83-116.

17. Calberson FL, Roeland J, De Moor RJ, Deroose CA (2007) The radix entomolaris and paramolaris: Clinical approach in endodontics. J Endod 33: 58-63.
18. Cantatore G, Berutti E, Castellucci A (2009) Missed anatomy: Frequency and clinical impact. Endod Topics 15: 3-31.

19. Vertucci FJ (2005) Root canal morphology and its relationship to endodontic procedures. Endod Topics 10: 3-29.

20. Ingle JL, Beveridge EE, Glick DH, Weichman JA (1994) Modern endodontic therapy. In: Ingle JL, Bakland LK, Endodontics. (4 $4^{\text {th }}$ edn), Williams and Wilkins, Baltimore, 27-53.

21. Weine FS, Healey NJ, Gerstein H, Evanson L (1969) Canal configuration in the mesiobuccal root of the maxillary first molar and its endodontic significance. Oral Surg Oral Med Oral Pathol 28: 419-425.

22. Cheung GS (1996) Endodontic failures-changing the approach. Int Dent J 46: 131-138.

23. Neaverth EJ, Kotler LM, Kaltenbach RF (1987) Clinical investigation (in vivo) of endodontically treated maxillary first molars. J Endod 13: 506-512.

24. Vertucci FJ (1984) Root canal anatomy of the human permanent teeth. Oral Surg Oral Med Oral Pathol 58: 589-599.

25. Wolcott J, Ishley D, Kennedy W, Johnson S, Minnich S (2002) Clinical investigation of second mesiobuccal canals in endodontically treated and retreated maxillary molars. $J$ Endod 28: 477-479.

26. Weine FS, Pasiewicz RA, Rice RT (1988) Canal configuration of the mandibular second molar using a clinically oriented in vitro method. J Endod 14: 207-213.

27. Ahmed HA, Abu-bark NH, Yahia NA, Ibrahim YE (2007) Root and canal morphology of permanent mandibular molars in a Sudanese population. Int Endod J 40: 766-771.

28. Loh HS (1990) Incidence and features of three-rooted permanent mandibular molars. Aust Dent J 35: 434-437.

29. Manning SA (1990) Root canal anatomy of mandibular second molars. Part II. C-shaped canals. Int Endod J 23: 40-45.

30. Melton DC, Krell KV, Fuller MW (1991) Anatomical and histological features of C-shaped canals in mandibular second molars. J Endod 17: 384-388.

31. Pomeranz HH, Eidelman DL, Goldberg MG (1981) Treatment considerations of the middle mesial canal of mandibular first and second molars. J Endod 7: 565-568.

32. Martinez-Berna A, Badanelli P (1983) Investigación clínica de molares inferiores con cinco conductos. Boletín de Información Dental 43: 27-41.

33. De Moor RJ, Deroose CA, Calberson FL (2004) The radix entomolaris in mandibular first molars: An endodontic challenge. Int Endod J 37: 789-799.

34. Carlsen O, Alexandersen V (1991) Radix paramolaris in permanent mandibular molars: Identification and morphology. Scan J Dent Res 99: 189-195.

35. Sperber GH, Moreau JL (1998) Study of the number of roots and canals in Senegalese first permanent mandibular molars. Int Endod J 31: 117-122.

36. Yew SC, Chan K (1993) A retrospective study of endodontically treated mandibular first molars in a Chinese population. J Endod 19: 471-473. 